\title{
General Review
}

\section{A nimal Models for the Study of Lower Extremity Chronic Venous Disease: Lessons Learned and Future Needs}

\author{
Michael C. Dalsing, MD, J ohn J . Ricotta, MD, Thomas Wakefield, MD, \\ Thomas G. Lynch, MD, and Kenneth Ouriel, MD, Indianapolis, Indiana, \\ Buffalo and Rochester, New York, Ann Arbor, Michigan, and Omaha, N ebraska
}

\begin{abstract}
The purpose of this review is to define animal models of chronic venous disease and to demonstrate how animal studies can impact our understanding and treatment of this disorder. To this end an extensive literature search was conducted highlighting potential animal models of chronic lower extremity venous disease. Scientific investigations using animals to study particular aspects of this disease are also reviewed. This review was conducted by members of the Committee on Research of the American Venous Forum to help provide direction for future venous research endeavors. Useful models of chronic venous occlusive disease involve controlled ligation of a major lower limb vein and multiple tributaries. Such a model can provide sustained venous hypertension and studies using this model have confirmed that an isodiametric graft can provide early hemodynamic relief. Models of primary, postphlebitic, and isolated chronic deep venous insufficiency are available for study. Valve repair or transplantation can positively impact the insufficiency observed in these models. Investigations into valve substitutes have generally been disappointing or are undergoing early evaluation. In conclusion, animal models for the study of some aspects of chronic venous disease do exist and have already affected our clinical approach to patients. The scientific study of basic pathophysiology, diagnostics, end-organ response, and long-term surgical treatments of this disorder in well-controlled animal experiments have not been conducted. (Ann Vasc Surg 1998;12:487-494.)
\end{abstract}

\section{INTRODUCTION}

A clear understanding of the pathophysiology of lower extremity chronic venous disease is lacking and one of the major reasons is a deficiency of animal models that mimic the human condition. As a

From the Department of Surgery, Section of Vascular Surgery, Indiana U niversity M edical Center, Indianapolis, Indiana (M.C.D.), Department of Surgery, Section of Vascular Surgery, University of Buffalo, Buffalo, N ew York (J .J.R.), Department of Surgery, Section of Vascular Surgery, University of Michigan, Ann Arbor, Michigan (T.W.), Department of Surgery, Section of Vascular Surgery, University of Nebraska Medical Center, Omaha, Nebraska (T.G.L.), and Department of Surgery, Section of Vascular Surgery, University of Rochester Medical Center, Rochester, N ew York (K.O.).

Correspondence to: M.C. Dalsing, MD, Indiana University Medical Center, Wishard Memorial Hospital, 1001 West Tenth Street, OPE 303, Indianapolis, IN 46202, USA. result, experimental animal studies to address the surgical treatment of this problem on a scientific level have been scarce and substantial clinical advancement in the treatment of this disorder has been hindered.

A renewed interest in the study of chronic venous diseases provides an impetus to review information on available animal models. A review of lessons learned from surgical investigations conducted in these models may provide a glimpse into what impact such studies have had and may have in the clinical arena. The direction of future animal studies is also considered.

\section{LITERATURE REVIEW Obstructive Models}

During the 1970s, the study of extensive acute venous thrombosis was in full swing. Selective control 
of a canine's femoral vessels while the remainder of the leg was subjected to tourniquet occlusion provided one model of total venous occlusion. ${ }^{1}$ If the femoral vein was occluded for 24 hours, one could expect a $33.3 \%$ mortality. Reducing this period of occlusion to 6 hours followed by femoral vein declamping resulted in a restoration of arterial flow without concomitant venous thrombosis. The study limbs demonstrated severe swelling, ecchymosis, and approximately $40 \%$ of limbs had extensive skin blebbing. A second canine model required ligation of all veins from the ipsilateral iliocaval junction to the femoral vein distal to the profunda including the contralateral hypogastric vein. The result was a $30 \%$ 1-day mortality. ${ }^{2}$ The high mortality and extensive limb damage resulting from such model designs were optimal for the study of phlegmasia cerulea dolens but unacceptable for long-term investigations.

Simple ligation of the femoral vein resulted in a dramatic increase in peripheral venous pressure immediately following ligation (20-40 torr increase). This was short-lived, however, in that the pressure dropped to one-half and then to two-fifths of the maximal pressure increase within 4 and 72 hours, respectively. ${ }^{3-5}$ Simple iliac vein ligation had a similar fate. ${ }^{6}$ No venous dilation nor lower limb edema was noted in these animals. An ipsilateral or cross femorofemoral vein bypass resulted in the immediate correction of distal venous hypertension. ${ }^{4,6} \mathrm{~A}$ lack of sustained elevated venous pressure distal to the ligature in these models was considered a factor in the overall poor primary patency of attempted reconstructions (29\%). ${ }^{6}$ Simple ligation of one major lower limb vein does not produce sustained distal venous hypertension necessary for a chronic occlusive model.

A large diameter $(1.5 \mathrm{~cm})$ high-flow side-to-side femoral artery to femoral vein fistula constructed distal to a femoral vein ligature increased the distal venous pressure to near arterial levels. ${ }^{7}$ Although venous hypertension is generated, this model does not reflect the clinical condition in that the hypertension is unrelenting and is of uncharacteristic severity.

Controlled ligation of multiple lower extremity veins provides a more realistic and workable model of chronic venous hypertension. In a greyhound, ligation of the external and internal iliac veins in addition to all side branches to just above the caudal femoral vein resulted in elevated distal venous pressures at rest and during exercise that was sustained for at least 15 weeks. $^{8}$ Lower limb edema resolved by 6 weeks but there was increased venous patterning over the lower abdomen. Several short-term
( $\leq 4$ hours) studies using this model have clarified some aspects of the surgical treatment of venous occlusive disease. ${ }^{9-11}$ Cross femoral vein to femoral vein bypass of a diameter less than that of the affected limb outflow tract only partially relieves distal venous hypertension and graft flow is poor. ${ }^{9}$ The addition of a distal arteriovenous fistula (dAVF) increased graft flow ( 400 $\mathrm{ml} / \mathrm{min})$ but also increased distal venous hypertension (8-9 times normal). ${ }^{9} \mathrm{An}$ isodiametric conduit relieved distal venous hypertension. 9,10 The addition of a high-flow dAVF ( $1200 \mathrm{ml} / \mathrm{min}$ ) was detrimental to venous pressure and induced undesirable physical symptoms. ${ }^{10}$ A more peripheral dAVF ( 200-400 ml/min) augmented flow without detrimental effects on distal venous pressures. ${ }^{11}$ An isodiametric cross femoral vein bypass using external jugular vein in addition to a sequential AVF resulted in a normalization of resting and postexercise distal venous pressures by 6 weeks and maintained this improvement after AVF ligation (follow-up 6 weeks). ${ }^{8}$ This model appears acceptable for investigating several aspects of the surgical treatment of chronic venous occlusive disease. Furthermore, studies already performed with this model clearly suggest that an isodiametric graft is required to maintain normal venous hemodynamics and that a dAVF of moderate flow may be helpful to maintain early patency.

Extensive ligation of bilateral hypogastric veins as well as the external iliac and all branches including the superficial femoral vein (SFV) on one side in a rabbit resulted in elevated distal venous pressures ( $\sim 5 \mathrm{mmHg}$ higher than the normal side) for at least 8 weeks. ${ }^{12}$ The creation of a small diameter (inferior epigastric vein to side of superficial femoral artery) dAVF that was ligated after 2 weeks reduced distal venous pressure postligation by almost onehalf when compared to control limbs. It was theorized that the improvement noted resulted from an increase in venous collateral size or number. This model may provide a less costly, yet surgically useful alternative for the study of chronic occlusive disease.

\section{Insufficiency Models}

Primary venous valvular incompetence is a recognized clinical entity. Interestingly, the crossbred merino sheep have totally or partially incompetent external jugular vein valves in $\sim 70 \%$ of cases. ${ }^{13}$ Merely decreasing the valve circumference ( 24\%) with a Venocuff ${ }^{\circledR}$ can restore competence. A suggestion that progressive dilation of the vein circum- 
Table I. Transplantation of valve containing venous segments to the superficial femoral or popliteal vein

\begin{tabular}{|c|c|c|c|c|c|c|}
\hline Method & Reference & $\begin{array}{l}\text { Delay to } \\
\text { usable } \\
\text { model } \\
\text { (weeks) }\end{array}$ & $\begin{array}{l}\text { Useable } \\
\text { model } \\
(\%)\end{array}$ & Donor valve & $\begin{array}{l}\text { Overall } \\
\text { patency } \\
(\%)\end{array}$ & $\begin{array}{l}\text { Competent } \\
\text { valves } \\
(\%)\end{array}$ \\
\hline \multicolumn{7}{|l|}{ Sclerosing agents } \\
\hline $5 \%$ ethanolamine & 15 & $6-11$ & 30 & EJ V/CSFV & 0 & 0 \\
\hline $1 \%$ sotradecol & 16 & $6-8$ & $100 *$ & EJ V/CSFV & 95 & $\mathrm{NA}^{\dagger}$ \\
\hline \multirow[t]{5}{*}{ Trauma and stasis } & 15 & $6+$ & 83 & CSFV & 50 & 50 \\
\hline & 15 & $6+$ & 83 & CSFV & 70 & $65^{\ddagger}$ \\
\hline & 15 & Regraft $^{\S}$ & NA & EJV & 40 & $80^{\ddagger}$ \\
\hline & 17 & $6+$ & 98 & CSFV & 67 & 39 \\
\hline & 17 & $6+$ & 98 & CSFV & 100 & $75^{\ddagger}$ \\
\hline \multirow[t]{4}{*}{ Valvulotomy } & $18-20$ & 3 & $\sim 100$ & EJV & 100 & 100 \\
\hline & $18-20$ & 3 & 100 & Experimental/EJ V & 100 & $87 * *$ \\
\hline & $18,19,21^{\dagger \dagger}$ & 3 & 100 & EJV & 20 & 20 \\
\hline & $18,19,21^{\dagger \dagger}$ & 3 & 100 & EJV & 83 & 83 \\
\hline
\end{tabular}

EJV, external jugular vein; CSFV, contralateral superficial femoral vein.

*Ligated femoral vein; therefore no recanalization possible.

${ }^{\dagger}$ At least $12 \%$ had no valves at sacrifice.

‡24-72 systems therapeutic heparin.

${ }^{\S}$ Only used after original transplant had failed.

**Adjuvant distal arteriovenous fistula.

${ }^{+\dagger}$ Transplant to popliteal vein location.

ference may be responsible for some cases of venous valvular insufficiency was addressed in this model by creating a $1 \mathrm{~cm}$ side-to-side AVF proximal to a competent valve. With a $45 \%$ increase in vein circumference, all four originally competent valves became incompetent within 7 days. ${ }^{13}$

A rat model was used to demonstrate that prolonged venous hypertension can lead to valvular incompetence and eventually complete cusp destruction. ${ }^{14} \mathrm{~A}$ side-to-side femoral AVF was surgically constructed and the proximal femoral and epigastric vein were then ligated. There was a $25 \%$ mortality from early cardiac failure. In those surviving, it was observed that the venous valves distal to the obstruction allowed retrograde flow within 1 day but demonstrated no obvious anatomic alteration. Eventually, however, cusp elongation, separation, and leakage were observed. At 4 months, it was difficult on gross inspection to recognize where valves had originally been located. This is an extreme hypertensive model which demonstrates what may happen to veins and their valves when subjected to prolonged high intravenous pressures. It is possible that following valve destruction and subsequent ligation of the fistula, this could be useful as a chronic insufficiency model but the operative mortality is most likely prohibitive.

Models of chronic venous insufficiency were ini- tially created by attempting to mimic a thrombophlebitic event. The injection of sclerosing agents was one such approach. An isolated segment of femoral vein was emptied of blood and filled with $5 \%$ ethanolamine for approximately 5 minutes and then declamped. ${ }^{15}$ Only $30 \%$ of animals were technically useful for transplantation due to densely adherent collaterals and surrounding soft tissue inflammation. No autogenous valve containing vein transplant remained patent or competent in shortterm follow-up (Table I). A more mild process was induced by injecting $1 \%$ sotradecol into a $4 \mathrm{~cm}$ segment of ligated femoral vein. ${ }^{16}$ Transplantation of a long length $(10-19 \mathrm{~cm})$ of valve containing external jugular vein was accomplished by avoiding the areas of sclerosis. Continuous patency rates were not documented and in at least $12 \%$ of cases no valves could be found at sacrifice (Table I). Thrombosis of the transplanted venous segment routinely lead to valvular incompetence. These experiences lead to the conclusion that a sclerosis model of deep venous insufficiency has an unpredictable outcome and is difficult to approach surgically in any event.

Subjecting a major lower limb vein to trauma and stasis was another method used to create a venous insufficiency model. This approach involved isolating a $2.5-4 \mathrm{~cm}$ long segment of femoral vein, emptying it of blood, and then crushing the vein 
with a needle holder. The isolated segment was filled with blood, bulldog clamps are applied above and below the area of trauma, and the dogs were reoperated in 2-4 days to remove the bulldog clamps. ${ }^{15,17}$ Recanalization generally resulted in an acceptable model for venous valve transplantation (Table I). The addition of 24 hours of perioperative systemic heparinization to the venous valve transplantation improved the primary patency rate to $\sim 85 \%$ with a reported valve competency rate of $\sim 70 \%$. Interestingly, if the transplant occluded, regrafting with an external jugular vein valvecontaining segment and utilizing 24 hours of systemic heparinization demonstrated a $40 \%$ patency yet a $80 \%$ overall competency rate. ${ }^{15}$ It was impossible to determine if the competent valves noted after venographically proven graft thrombosis had actually been involved with the thrombotic process. It appears that this model may mimic the clinical situation, can be used for valve transplantation experiments, and may require perioperative and possibly even prolonged heparinization for optimal results. A second interesting observation is that not all venous valves are rendered incompetent when subjected to a thrombotic event.

A greyhound model of lower limb venous valvular insufficiency with a low model failure rate (Table I) and uniquely studied by intravenous pressure measurements has been described. ${ }^{18,19}$ This model was created by introducing a valvulotome into the lower limb venous system via a lateral saphenous vein cutdown at the paw and advancing it proximally into the inferior vena cava. The dog was then elevated to a standing position and the valvulotome was rapidly pulled distally to disrupt all of the venous valves. This is a model of isolated deep venous insufficiency since the greyhound has no significant superficial or perforator veins nor a large calf muscle to complicate the picture. The intravenous pressure measurements (venous filling time [VFT], ambulatory venous pressure [AVP], $90 \%$ of venous refilling time [ $\left.\mathrm{VRT}_{90}\right]$ ) mimicked tracings found while studying patients with venous insufficiency. ${ }^{18,19}$ Transplanting a competent contralateral SFV valve-containing vein segment to the SFV Iocation on the incompetent side resulted in correction of the VFT and improvement in the $\mathrm{VRT}_{90}$ but the AVP was not improved. ${ }^{20}$ Transplantation of an external jugular vein (EJ V) valve into an incompetent popliteal venous system generally resulted in thrombosis unless a dAVF was added (Table I). ${ }^{21}$ With the use of a temporary dAVF ( $750 \mathrm{ml} / \mathrm{min})$, five of six grafts were patent with normal appearing valves on gross inspection. The AVP was consistent with a normal limb and there was improvement of the $\mathrm{VRT}_{90}{ }^{21}$ Using this model it does appear that venous valve transplantation can impact the venous hemodynamics of limbs with chronic venous insufficiency. The final hemodynamic result is dependent upon the location of valve implantation. The more distal the valve transplant, the greater the improvement in AVP. Another lesson learned was that the more distal the valve transplant, the more critical was the need for an adjuvant dAVF or at least some adjuvant method to maintain early patency.

\section{Venous Valve Substitutes}

The remaining major surgical study of lower extremity chronic venous disease in animals has been a search for a venous valve substitute.

A venous valve constructed from autogenous vein in the fashion of Eiseman and Malette ${ }^{22}$ has been investigated as a substitute for a normal venous valve of the lower extremity (Table II). The technique basically involves an intusseption of the vein into itself with an appropriate cusp made by two sutures placed at $180^{\circ}$ angles from each other to hold the inner vein wall in the correct position. ${ }^{20,23}$ In all reported studies, only operative heparinization was administered and no long-term anticoagulation was provided. Short-term patency was excellent with $90 \%-100 \%$ of valves competent at physiologic pressures. When used to correct the hemodynamic consequences of chronic venous insufficiency by transplantation to the SFV location, the VRT 90 was improved modestly but not the VFT that suggested that the valve was not as hemodynamically responsive as a native valve. ${ }^{20} \mathrm{~A}$ modification of this type of venous valve involved thinning the adventia and a part of the media to result in a thin valve cusp after intusseption. ${ }^{24}$ The valve opened at a pressure of $<3 \mathrm{~cm}$ water and closed at a pressure between 3 and $5 \mathrm{~cm}$ of water and could withstand physiologic pressure changes. Without the aid of prolonged heparinization, a thin layer of thrombus along the cusp wall resulted in valve incompetence. These studies suggest that autogenously constructed venous valves may be a reasonable substitute for native valves. However, it must be cautioned that some of these valves appear more prone to thrombosis and less responsive in a hemodynamic sense than is a native valve.

An off-the-shelf valve for use in transplantation would greatly facilitate the surgical process. Attempts to provide such a valve have been investigated (Table II). Transplantation of a valve containing vein from one dog as a fresh allograft to another while ignoring rejection issues resulted in failure. ${ }^{17}$ 
Table II. Experimental venous valves as substitutes for an autogenous valve

\begin{tabular}{|c|c|c|c|c|c|c|c|c|c|}
\hline Material & $\begin{array}{l}\text { Refer- } \\
\text { ence }\end{array}$ & $\begin{array}{l}\text { Donor } \\
\text { material }\end{array}$ & $\begin{array}{l}\text { Trans- } \\
\text { plant } \\
\text { site }\end{array}$ & $n$ & $\begin{array}{l}\text { Overall } \\
\text { patency } \\
(\%)\end{array}$ & Follow-up & $\begin{array}{l}\text { Overall } \\
\text { compe- } \\
\text { tence } \\
(\%)\end{array}$ & $\begin{array}{l}\text { Systemic } \\
\text { antico- } \\
\text { agulation }\end{array}$ & $\begin{array}{l}\text { Pressure } \\
\text { tested to }\end{array}$ \\
\hline \multicolumn{10}{|l|}{ Autograft } \\
\hline $\begin{array}{c}\text { E-M* type } \\
\text { valve }\end{array}$ & 23 & SFV & SFV & 6 & 100 & 1-112 days & 100 & 0 & $250 \mathrm{~cm} / \mathrm{H}_{2} \mathrm{O}$ \\
\hline $\begin{array}{l}\text { E-M* type } \\
\text { valve }\end{array}$ & 20 & EJV & SFV & 7 & 100 & 6-88 weeks & 90 & 0 & - \\
\hline \multirow{2}{*}{$\begin{array}{l}\text { Modified } \\
\text { E-M* type } \\
\text { valve }\end{array}$} & 24 & EJV & SFV & 6 & 100 & 1 week & 33 & 0 & $300 \mathrm{mmHg}$ \\
\hline & 24 & EJV & SFV & 3 & 100 & 7-13 days & 100 & $\begin{array}{l}\text { Chronic } \\
\text { heparin }\end{array}$ & $300 \mathrm{mmHg}$ \\
\hline \multicolumn{10}{|l|}{ Allograft } \\
\hline Fresh & 17 & SFV & SFV & 14 & 7 & 4 weeks & 0 & $\begin{array}{l}\text { Heparin } \\
24 \text { hours }\end{array}$ & - \\
\hline $\begin{array}{c}\text { Glutaraldehyde } \\
\text { preserved }\end{array}$ & 25 & SFV & SFV & 10 & 80 & 7 weeks & 25 & $\mathrm{dAVF} \mathrm{F}^{\dagger}$ & - \\
\hline \multirow[t]{2}{*}{ Cryopreserved } & 29 & SFV & SFV & 4 & 50 & 3 weeks $^{\ddagger}$ & 50 & $\mathrm{dAVF}$ & - \\
\hline & & SFV & SFV & 4 & 100 & 3 weeks $^{\ddagger}$ & 100 & $\mathrm{dAVF}$ & - \\
\hline \multicolumn{10}{|l|}{ Heterograft } \\
\hline Glutaraldehyde & 26 & Umbilical vein & $\begin{array}{l}\text { Jugular } \\
\text { vein }\end{array}$ & 10 & 0 & 3 days & 0 & Coumadin & - \\
\hline \multicolumn{10}{|l|}{ Mandril fitted } \\
\hline \multicolumn{10}{|l|}{ Synthetic } \\
\hline Mandril fitted & 26 & $\begin{array}{l}\text { Liquid } \\
\text { pellethane }\end{array}$ & $\begin{array}{l}\text { Jugular } \\
\text { vein }\end{array}$ & 10 & 0 & 8 days & 0 & Coumadin & $120 \mathrm{mmHg}$ \\
\hline \multirow[t]{2}{*}{ Manufactured } & 27 & $\begin{array}{l}\text { Platinum or } \\
\text { pyrite-carbon } \\
\text { covered } \\
\text { titanium }\end{array}$ & SFV & 3 & 100 & $\sim 3$ months & 100 & 0 & $100 \mathrm{mmHg}$ \\
\hline & 28 & $\begin{array}{l}\text { Platinum or } \\
\text { pyrite-carbon } \\
\text { covered } \\
\text { titanium }\end{array}$ & SFV & 3 & 0 & 3-24 months & 0 & 0 & $100 \mathrm{mmHg}$ \\
\hline
\end{tabular}

SFV, superficial femoral vein; EJV, external jugular vein; dAVF, distal arteriovenous fistula.

*Eiseman-Malette. ${ }^{48}$

${ }^{+}$Adjuvant continuously functioning dAVF.

${ }^{\ddagger}$ Post dAVF ligation.

Glutaraldehyde preserved allografts even when supported by a continually functioning dAVF but became incompetent in short order. ${ }^{25}$ The umbilical vein can be frozen, cleaned, and then fitted over an aluminum mandrel and fixed with glutaraldehyde to sculpture it into a bicuspid valve. ${ }^{26}$ All $10 \mathrm{im}$ plants failed within 3 days. The same aluminum rod design was used to fashion liquid pellethane into a venous valve. All implanted valves clotted in 8 days. ${ }^{26}$ Platinum or pyrite carbon-covered titanium center-hinged bileaflet valves have been implanted into the femoral location of three dogs. ${ }^{27}$ The patency and competence of these valves appeared to be good in early follow-up. ${ }^{27}$ Two-year results, however, demonstrated the valves to be rendered nonfunctional by extensive neointimal hyperpla- sia. $^{28}$ The most recent studies have concentrated again on allografts but preserved by a more gentle process. Dog erythrocyte antigen (DEA) matched cryopreserved venous valves have been transplanted into canine models with lower limb venous insufficiency. Supported by a dAVF for 3-6 weeks, the transplants have remained patent and competent for $\sim 3$ weeks following dAVF ligation. ${ }^{29}$ Lower limb venous hemodynamics were improved similar to that observed after implantation of an Eiseman/ Malette type valve. No long-term studies are available for this valve. Even though the cryopreserved allograft venous valve has shown some early promise, as yet, all other off-the-shelf prototypes either preserved allograft or synthetic have not proven to be a viable substitute for a native venous valve. 


\section{DISCUSSION}

The optimal animal model for the study of chronic venous disease would, of course, exactly mimic the human condition. The animal would have a natural propensity for venous thrombosis or primary venous disease which would translate into obstruction or insufficiency in a delayed but timely fashion. A close similarity in the animal's clotting cascade and platelet interactions to that of the human would simplify the study of surgical treatment and adjuvant postoperative requirements. The animal would have a lower extremity that closely resembles the human with a functional calf musculature. Walking upright would be beneficial such that the sequelae of the disease could be observed over time. Finally, the animal would be sufficiently tall (when standing) to allow hemodynamic study and sufficiently large to allow surgical interventions. This ideal model does not exist.

One of the controversial areas of any animal research involving vascular conduits (bypass grafts, valve substitutes, etc.) is the coagulation, platelet, and hematologic differences within mammalian species. This is an area largely ignored in previous animal studies of chronic venous disease. There is information available, however, and one excellent review considers a majority of these variables for most species amenable to surgical interventions from the rabbit to the nonhuman primate. ${ }^{30}$ In select areas, one or another species has coagulation and other hematologic parameters similar to man and could be selected for study based on this knowledge. Certainly, if one is utilizing the often studied dog model, normalization of platelet reactivity with the use of antiplatelet agents would be reasonable ${ }^{31}$ and has been recognized as important by many investigators. As the study of valve substitutes using synthetics or processed allografts becomes more active, the study of nonhuman primates may become imperative to address venous coagulation concerns. A nonlethal method of testing these materials in this high-cost model has been reported and should be considered. ${ }^{32}$ As our ability to modify the coagulation systems of animals becomes more refined, less traumatic models of acute deep venous thrombosis ${ }^{33}$ may create animals with chronic disease. This serendipitous event may provide a more realistic model with which to study the sequelae and surgical treatment of chronic venous disease. A more in-depth discussion of this topic is beyond the scope of the current manuscript but certainly any future research in which thrombosis is such a crucial event must address these concerns.

No current animal model mimics man's ability to walk upright nor possess the human calf muscle pump so important in human venous hemodynamics. Many animals, however, are sufficiently large to approach surgically and some sufficiently tall to allow hemodynamic testing and specific surgeries such as valve transplantation. It was a learning experience to find that a greyhound could be used as a hemodynamic model of venous insufficiency while the shorter statured mongrel was not appropriate since intravenous pressure changes were not sufficiently different to separate a normal from an abnormal limb. Certainly, nonhuman primates do more closely resemble man in some aspect but may not be appropriate models from a practical standpoint. The cost of purchase and maintenance must be considered as must the ease of surgical and anesthetic care. Obviously, these factors have currently made the dog the primary model for the study of venous surgery. It may be that the thrombus-prone canine may be the optimal model for most research but when specific cardiovascular, coagulation or hematologic functions become of primary concern then other animals including nonhuman primates may be more appropriate.

The availability of chronic lower extremity venous disease models has allowed some in-depth evaluation of surgical bypass procedures in the acute setting as enumerated in the body of this work. However, little research yet exists on the basic pathophysiology of chronic venous occlusive disease of the lower extremity. Evaluation of current models could provide hemodynamic information vital to the manufacture of more precise clinical diagnostic tools. Our lack of ability to precisely characterize and define this disease has been a major clinical obstacle to improved treatment. The long-term study of venovenous bypass grafts especially with hemodynamic correlation is still lacking. This is especially true of synthetic grafts, conduits prone to thrombosis in the venous system, yet possibly the only graft of sufficient diameter to correct the hemodynamic consequences of significant clinical venous occlusive disease. ${ }^{10}$ Animal models are particularly well suited for studying such conduits, modifications to them (e.g., endothelial seeding ${ }^{34} \pm$ genetic engineering or graft coatings with agents such as thrombolytics or heparin), and the study of any potential new materials (e.g., stents, ${ }^{35}$ specific polymers). Adjuvants to surgery can also be evaluated in appropriately chosen animal models (e.g., low molecular weight heparin, low dose warfarin). A more in-depth study into the proper size and time to closure of the often useful dAVF is fruitful ground for animal investigation. One may also explore the actual need for bypass grafting in view of 
the possibility of enhanced collateral size (e.g., an isolated dAVF, ${ }^{12}$ drugs to enhance collateral dilatation [nitric oxide ${ }^{36}$ ]), or new collateral growth if veins mimic the response of arteries (vascular endothelial derived growth factor ${ }^{37}$ ).

Realizing that animal studies of chronic venous insufficiency have set the framework for clinical investigations and have confirmed several clinical impressions, still much remains a mystery and is amenable to animal investigation. A basic understanding of the underlying pathophysiology and appropriate diagnostic tools for it's evaluation are lacking in the clinical arena and can be studied in appropriate animal models. The proper location of competent valves in the lower extremity (SFV to tibial) as well as the need for more than one valve for the correction of chronic venous insufficiency requires study. Evaluation of the optimal method to ensure long-term valve function is a much needed area of controlled investigation. The optimal size and time to closure for an adjuvant dAVF can be more precisely determined. Other adjunctive measures of potentially more benefit (e.g., low molecular weight heparin) require experimental consideration. Is external support of valves useful in the long term or is it detrimental due to local scarring? The area of valve substitutes is a field conducive to and requiring animal investigation (e.g., cryopreserved valves, histocompatible fresh al lografts, synthetics \pm coatings). These are but a few of the areas concerning chronic venous insufficiency still awaiting scientific study.

The area of animal investigation most ignored but possibly of prime importance is the study of the end-organ response to chronic venous disease. The majority of clinical problems associated with deep venous disease are manifested ultimately in the tissues around the ankle. Edema, skin dermatitis, and ulceration are three obvious sequelae. Several hypothesis have been proposed to explain the events leading to these sequelae based upon observations of the microvascular in humans. ${ }^{38-41}$ However, to confirm these hypothesis, research must be performed in an intact living animal where control of multiple variables is possible. The complex interactions that must take place to result in the final pathologic condition can be observed in no other manner. There are models available for the shortand long-term study of at least some aspects of the end-organ response to chronic venous occlusive disease. ${ }^{42-46}$ Short-term studies of venous insufficiency could be conducted in the anesthetized upright dog. ${ }^{18,19}$ An animal model of long-term venous insufficiency with obvious clinical sequelae in the lower extremity is presently elusive. Such stud- ies are basic to our understanding of the impact of venous disease on the lower leg and to allow some method of formulating potential treatments to modify it. We need to know the histological and functional effect of this disease on large to small arterioles, venules, capillaries, lymphatics, skin, muscle, and subcutaneous tissue. Does chronic venous disease eventually lead to lymphatic destruction and little chance of permanent cure? What impact does chronic venous disease have on bloodborn products entering the limb (e.g., white cells, platelets, macromolecules) and how is the interstitial fluid and the matrix in which it lies altered? What effect do different drugs have on these adaptations to the disease state (e.g., pentoxyfilline ${ }^{47}$ )? What effect does surgical treatment have on the end-organ at various stages of the disease? Would earlier intervention prevent a progression of the disease process to a state of no return?

This review provides a historical perspective of the animal models available for the study of lower limb chronic venous disease. Previous studies using these models have directed and continued to direct the surgical care of this disorder. However, most aspects of chronic venous disease have not been studied by the scientific method and it appears that animal models are often indispensable to these investigations. It is hoped that bright young minds will choose to address some of the very difficult questions that remain concerning a very old yet very misunderstood disorder.

\section{REFERENCES}

1. Stallworth J M, Najib A, Kletke RR, Ramirez A. Phlegmasia cerulea dolens: An experimental study. Ann Surg 1967;165: 860-868.

2. Bernhard VM, Gelford ET, Corhran GA, Schmahl TM. Isolated arteriovenous limb perfusion in experimental iliofemoral venous thrombosis. Curr Topics Surg Res 1970;2:503510.

3. Hobson RW, Howard EW, Wright CB, Collins GJ, Rich NM. Hemodynamics of canine femoral venous ligation: Significance in combined arterial and venous injuries. Surgery 1973; 74:824-829.

4. Wright CB, Swan KG. Hemodynamics of venous repair in the canine hind limb. J Thorac Cardiovasc Surg 1973;65: 195-199.

5. Wright CB, Swan KG. Hemodynamics of venous occlusion in the canine hindlimb. Surgery 1973;73:141-146.

6. Harris J. Cross leg venous graft for the relief of unilateral lower limb venous obstruction. Surg Gynecol Obstet 1965;1232-1236.

7. Dart $\mathrm{CH}$, J ohnson G, Peters RM, Wamack NA. Hemodynamic effects of femoral venous occlusion before and after an acute arteriovenous fistula. Ann Surg 1966;164:190-196.

8. Lalka SG, Malone J M, Cosentino C, Reinert RL, Bernhard VM. Canine model for surgical correction of chronic venous hypertension. J Surg Res 1988;44:359-370. 
9. Lalka SG, Cosentino C, Malone J M, Reinert RL, Bernhard VM. Hemodynamics of revascularization for iliofemoral venous occlusion: A short-term canine model. J Vasc Surg 1988;8:592-599.

10. Lalka SG, Unthank J L, Lash J M, McGue J G, Cikrit DF, Sawchuk AP, Dalsing MC. Hemodynamic effects of varied graft diameters in the venous system. Surgery 1991;110:73-79.

11. Lalka SG, Unthank J L, McGue JG, Cikrit DF, Sawchuk AP, Dalsing MC. Arteriovenous fistulas as adjuncts to venous bypass grafts. J Invest Surg 1991;4:125-136.

12. Sawchuk AP, Dalsing MC, Emerick SC, Waller BF, Reilly MK, Broadie TA. A temporary distal arteriovenous fistula improves venous hemodynamics in a model of venous occlusion. Surgery 1987;102:256-262.

13. J essup G, Lane RJ . Repair of incompetent venous valves: A new technique. J Vasc Surg 1988;8:569-575.

14. Van Bemmelen SP, van Papendrecht AAH, Hodde KC, et al. A study of valve incompetence that developed in an experimental model of venous hypertension. Arch Surg 1986;121: 1048-1052.

15. Waddell WG, Prudhomme P, Ewing J B, et al. Venous valve transplantation in postphlebitic and post-thrombotic veins. Arch Surg 1967;94:826-834.

16. Cerino M, McGraw JY, Luke J C. Autogenous vein graft replacement of thrombosed deep veins. Experimental approach to the treatment of the postphlebitic syndrome. Surg 1964;55:123-134

17. McLachlin AD, Carroll SE, Meads GE, et al. Valve replacement in the recanalized incompetent superficial femoral vein in dogs. Ann Surg 1965;162:446-452.

18. Lalka SG, Unthank J L, Dalsing MC, Cikrit DF, Sawchuk AP. Venous hemodynamics in a chronic venous valvular insufficiency model. Arch Surg 1990;125:1579-1583.

19. Dalsing MC, Zukowski AJ , Unthank J L, Lalka SG, Sawchuk AP, Cikrit DF. Details of a canine venous insufficiency model. J Invest Surg 1994;7:85-93.

20. Dalsing MC, Lalka SG, Unthank J L, Grieshop RJ , Nixon C, Davis T. Venous valvular insufficiency: Influence of a single venous valve (native and experimental). J Vasc Surg 1991; 14:576-587.

21. Dalsing MC, Lalka SG, Zukowski AJ , Unthank J L, Sawchuk AP, Cikrit DF. Valve transplantation to the canine popliteal vein: The utility of a distal arteriovenous fistula and the hemodynamic result of a single functional valve. J Vasc Surg 1994;20:736-743.

22. Eiseman B, Malette W. An operative technique for the construction of venous valves. Surg Gynecol Obstet 1953;97: 731-734.

23. Wilson NM, Rutt DL, Browse NL. In situ venous valve construction. Br J Surg 1991;78:595-600.

24. Rosenbloom MS, Schuler JJ, Bishara RA, Ronan SG, Flanigan DP. Early experimental experience with a surgically created, totally autogenous venous valve: A preliminary report. J Vasc Surg 1988;7:642-646.

25. Kaya M, Grogan J B, Lentz D, Tew W, Raju S. Glutaraldehyde-preserved venous valve transplantation in the dog. J Surg Res 1988;45:294-297.

26. Hill R, Schmidt S, Evancho M, Hunter T, Hillegass D, Sharp W. Development of a prosthetic venous valve. J Biomed Mater Res 1985;19:827-832.

27. Taheri SA, Rigan $D$, Wels $P$, Mentzer $R$, Shores RM. Experimental prosthetic vein valve. Am J Surg 1988;156:111-114.
28. Taheri SA, Schultz RO. Experimental prosthetic vein valve. Long-term results. Aniology 1995;46:299-303.

29. Burkhart HM, Fath SW, Dalsing MC, et al. Experimental repair of venous valvular insufficiency using a cryopreserved venous valve allograft aided by a distal arteriovenous fistula. J Vasc Surg 1997;26:817-822.

30. Didisheim P. Hematologic differences among certain mammalian. In Herring M, Glover J L, eds. Endothelial Seeding in Vascular Surgery. Orlando, FL: Grune \& Stratton, 1987, pp 7-16.

31. Kaplan S, Marcoe KF, Sauvage LR, et al. The effect of predetermined thrombotic potential of the recipient on smallcaliber graft performance. J Vasc Surg 1986;3:313-320.

32. Shoenfeld NA, Yeager A, Connolly R, et al. A new primate model for the study of intravenous thrombotic potential and it's modification. J Vasc Surg 1988;8:49-54.

33. Wakefield TW, Wrobleski SK, Sarpa MS, Talor FB, Esmon CT, Cheng A, Greenfield LJ . Deep venous thrombosis in the baboon: An experimental model. J Vasc Surg 1991;14:588598.

34. Menconi MJ, Wheeler HB, Rohrer MJ, et al. Experimental femoral vein reconstruction with expanded polytetrafluorethylene grafts seeded with endothelial cells. Cardiovasc Surg 1993;1:362-368.

35. Parsson H, Norgren L, Ivancev K, et al. Thrombogenicity of metallic vascular "stents" in arteries and veins-An experimental study in pigs. Euro J Vasc Surg 1990;4:617-623.

36. Bowman AJ, Chen CP, Ford GA. Nitric oxide mediated venodilator effects of nebivolol. Br J Clin Pharmacol 1994; 38:199-204.

37. Bauters C, Asahara T, Zheng LP, Takeshita S, Bunting S, Ferrara N, Symes J F, Isner J M. Site-specific therapeutic angiogenesis after systemic administration of vascular endothelial growth factor. J Vasc Surg 1995;21:314-324.

38. Browse NL, Burnand KG. The cause of venous ulcerations. Lancet 1982;2:243-245.

39. Coleridge-Smith PD, Thomas P, Scurr JH, Dormandy JA. Causes of venous ulceration: A new hypothesis. Br Med J 1988;296:1726-1727.

40. Michael CC. Microvascular permeability, "venous" stasis and edema. Int Angiol 1989;8:9-13.

41. Falongi V, Eaglstein WH. The "trap" hypothesis of venous ulceration. Lancet 1993;341:1006-1007.

42. Bell DR, Mullins RJ : Effects of increased venous pressure on albumin- and IgG-excluded volumes in muscle. Am J Physiol 1982;242: $\mathrm{H} 1044-\mathrm{H} 1049$.

43. Renkin EM, J oyner WL, Sloop CH, Watson PD. Influence of venous pressure on plasma-lymph transport in the dog's paw: Connective and dissipative mechanisms. Microvasc Res 1977; 14:191-204

44. Burnand KG, Clemenson G, Whimster I, Gaunt J, Browse $\mathrm{NL}$. The effect of sustained venous hypertension on the skin capillaries of the canine hind limb. Br J Surg 1982;69:41-44.

45. Leach RD. Venous ulceration, fibrinogen and fibrinolysis. Ann R Coll Surg Engl 1984;66:258-263.

46. Bryla P, Piotrowicz W, Galkowska H, Olszewski WL. Effect of acute venous hypertension on erythrocyte, leukocyte, and plasma protein extravasation in the dog hindlimb. Lymphology 1989;22:67-75

47. Colgan MP, Moore DJ, Shanik DG. New approaches in the medical management of venous ulceration. Angiology 1993; 44:138-142. 